\title{
WAWASAN HADIS TENTANG ALAT DAN MEDIA PENDIDIKAN
}

\author{
Zainal Abidin \\ Fakultas Tarbiyah dan Ilmu Keguruan IAIN Lhokseumawe \\ Email: zainalabidin.sthi@gmail.com
}

\begin{abstract}
Hadith is Everything that is based on the Prophet Muhammad PBUH from words, deeds, taqrir or nature. Educational tools are everything that serves to support the achievement of educational goals or anything that helps the implementation of education in achieving educational goals, both tools in the form of objects and nonobjects. Whereas the media of education or learning is an object that can be sensed, especially vision and hearing, both inside and outside the classroom, which is used as a liaison tool (communication media) in the process of interaction in teaching and learning to improve the effectiveness of student learning outcomes. In the history of his life, the Prophet Muhammad PBUH being the Messenger of Allah also had a role as an educator who delivered and taught the message of the great Islamic religion. In the process of teaching the Messenger of Allah. has used tools and media in the form of objects or non-objects that helped him in educating students who at that time were early Muslims who in science terms Hadith known as the Companions of the Prophet. Recorded in the master books of the Prophet's Hadith, Muhammad PBUH have used several educational tools and media in the process of teaching to Muslims at that time known as the generation of friends in the term of Hadith science. The tools and media that were used by the Prophet Muhammad. is the person of the Prophet Muhammad PBUH itself then some things like silk and gold, sun, moon, pulpit, fingers, pictures and photos.
\end{abstract}

\section{Kata kunci: Hadis, Alat dan Media Pembelajaran}

\section{PENDAHULUAN}

Hadis memberikan keteladanan secara baik dan universal dalam pendidikan. Hadis juga merupakan rekaman peri kehidupan Rasulullah Saw. yang kemudian dibukukan dalam kitab-kitab induk Hadis yang kemudian dikenal dengan istilah Kutub As-Sittah (Enam kitab induk Hadis seperti Shahih Bukhari, Shahih Muslim, Sunan Abu Daud, Sunan Tirmizi, Sunan An-Nasa'i, Sunan Ibnu Majah).

Dalam kaitannya dengan dunia pendidikan Islam, hadis merupakan sumber inspirasi dan akar keteladanan, karena Rasulullah Saw. adalah seorang manusia yang dipilih Allah Swt. untuk memberi penjelasan dan teladan tentang ayat-ayat Alquran sebagaimana termaktub dalam Surat Al-Ahzab (33) ayat 21. Selanjutnya sebagai sumber inspirasi dan akar keteladanan dalam dunia pendidikan Islam, Hadis sepatutnya di gali dan di elaborasi secara mendalam oleh kaum muslimin terutama praktisi dan 
pakar pendidikan Islam agar proses pendidikan Islam sesuai dengan garis-garis besar yang telah di sabdakan dan dipraktekkan oleh Nabi Muhammad Saw. 14 abad yang silam. Karena tanpa pengkajian yang serius-mendalam, pemahaman yang baik-benar juga pelaksanaan yang sesuai dengan Alquran dan Hadis mustahil tujuan dan cita-cita pendidikan Islam tercapai seutuhnya.

Oleh sebab itu, tulisan ini memaparkan praktik pendidikan Islam yang telah dilakukan oleh Nabi Muhammad Saw. 14 abad yang lalu khususnya tentang alat dan media yang di gunakan Nabi Muhammad Saw. dalam mendidik para sahabat yang hidup di sekeliling Nabi Muhammad Saw. walaupun sebagian alat dan media pendidikan tersebut tidak bisa dipergunakan untuk zaman sekarang ini akan tetapi setidaknya menjadi sumber inspirasi untuk pengembangan alat atau media pendidikan untuk masa sekarang dan masa selanjutnya.

\section{PEMBAHASAN}

\section{Pengertian alat pendidikan}

Alat pendidikan adalah segala sesuatu yang berfungsi mendukung tercapainya tujuan pendidikan. Anshari (1983) berpendapat bahwa alat pendidikan ialah segala sesuatu yang membantu terlaksananya pendidikan didalam mencapai tujuan pendidikan, baik alat berupa benda maupun bukan benda. Syafaruddin dkk (2009: 111) mengatakan secara sederhana bahwa alat pendidikan dipahami adalah alat yang terkait dengan perlengkapan dalam pelaksanaan pendidikan. Di sekolah misalnya, alat pendidikan dapat berupa buku teks, alat peraga, alat klasikal seperti white board, over head projector, papan tulis, kapur tulis, gambar-gambar, Laser Compact Disk (LCD). Demikan pula keberdaan perpustakaan dan laboratorium berfungsi sebagai pendukung proses pendidikan. Sedangkan alat pendidikan di rumah terkait dengan alat bukan benda bisa berupa keteladanan, pembiasaan, nasihat, ganjaran, reward and punishment (hadiah dan sanksi).

\section{Pengertian media pendidikan}

Secara bahasa kata media berasal dari bahasa latin medius yang secara harfiah berarti tengah, perantara, atau pengantar. Dalam bahasa Arab, media adalah perantara (وسيلة/ وسنا ئل), pengantar pesan atau pengirim kepada penerima pesan. Gerlach dan Ely sebagaimana di kutip Bukhari Umar (2010) menyatakan bahwa media apabila 
dipahami secara garis besar adalah manusia, materi, atau kejadian yang membangun kondisi yang membuat siswa mampu memperoleh pengetahuan, keterampilan, atau sikap. Dalam pengertian ini guru, buku teks, dan lingkungan sekolah merupakan media. Dengan demikian media pendidikan itu terdiri atas manusia dan bukan manusia.

Media pendidikan adalah jalan atau cara yang dapat ditempuh untuk menyampaikan bahan atau materi pendidikan kepada peserta didik agar terwujud keperibadian muslim. Juga mengandung pengertian segala sesuatu yang dapat digunakan untuk menuntut atau membimbing peserta didik dalam mencapai tujuan pendidikan, sehingga mampu menjadi kepribadian muslim yang diridhai Allah.

Menurut Zakiah Daradjat(1995), media pendidikan atau pembelajaran adalah suatu benda yang dapat diindrai, khususnya penglihatan dan pendengaran, baik yang terdapat di dalam maupun di luar kelas, yang digunakan sebagai alat bantu penghubung (media komunikasi) dalam proses interaksi belajar mengajar untuk meningkatkan efektifitas hasil belajar siswa.

Sedangkan Asnawir dan Basyiruddin Usman(2002:11) menjelaskan bahwa media merupakan sesuatu yang bersifat menyalurkan pesan dan dapat merangsang pikiran, perasaan, dan kemauan audiens (siswa) sehinga dapat mendorong terjadinya proses belajar pada dirinya.

Sehingga dapat dipahami, bahwa media pembelajaran atau pendidikan merupakan alat bantu atau sarana yang dijadikan sebagai perantara atau piranti komunikasi untuk menyampaikan pesan atau informasi berupa ilmu pegetahuan dari berbagai sumber ke penerima pesan atau informasi guna mencapai tujuan pembelajaran.

\section{Pengertian Hadis}

Menurut Ibn Manzur(1992: 131), kata 'Hadis' berasal dari bahasa Arab, yaitu al-Hadits, jamaknya al-ahadits, al-haditsan dan al-hudtsan. Secara etimologis kata ini memiliki banyak arti diantaranya al-jadid (yang baru) lawan dari al-qadim (yang lama) dan al-khabar yang berarti berita atau kabar.

Sedangkan Muhammad Mustafa Azami (1977: 1) mendefenisikan hadis secara etimologis adalah "komunikasi, cerita, percakapan baik dalam konteks agama atau duniawi, atau dalam konteks sejarah atau peristiwa dan kejadian aktual". 
Penggunaannya dalam bentuk kata sifat mengandung arti al-jadid yaitu yang baharu, lawan dari al-qadim, yang lama. Dengan demikian pemakaian kata hadis disini seolaholah dimaksudkan untuk membedakannya dengan Alquran yang bersifat qadim. Kata Hadis terulang sebanyak 23 kali dalam Alquran dalam bentuk tunggal dan 5 kali dalam bentuk jamak. Keseluruhan pengertiannya sama dengan pengertian hadis diatas.

Secara terminologis, Ibn Hajar al-'Asqalani mendefinisikan Hadis sebagai berikut : ما يضاف الي النبي صلي الله عليه وسلم

“Segala sesuatu yang disandarkan kepada Nabi Saw."(Jalaluddin As-Suyuti: 1995, 15)

Menurut ulama yang lain definisi diatas masih umum sekali sehingga memerlukan batasan yang terperinci lagi. Definisi yang lebih rinci dikemukakan Mahmud at-Tahan (2001: 14) yakni:

$$
\text { ما اضيف الي النبي صلي الله عليه وسلم من قول او فعل او تقرير او صفة }
$$

"Segala sesuatu yang disandarkan kepada Nabi Saw dari perkataan, perbuatan, taqrir atau sifat".

Sedangkan Ibn Taimiyyah menfinisikan lebih sempit lagi dengan memberi batasan sesudah kenabian sebagai berikut :

$$
\text { ما حدث به عنه صلي الله عليه وسلم بعد النبوة من قولهه وفعله واقراره }
$$

"Seluruh yang diriwayatkan dari Rasul Saw sesudah kenabian beliau yang terdiri atas perkataan, perbuatan dan ikrar beliau”. (Muhammad Jamal ad-Din al-Qasimi: 1980)

\section{Hadis-hadis tentang alat dan media pendidikan}

Dalam kehidupannya, Nabi Muhammad Saw. menjadi Rasulullah Saw. juga memiliki peran sebagai pendidik yang menyampaikan dan mengajarkan risalah agama Islam yang agung. Dalam proses pengajaran tersebut Rasulullah Saw. telah menggunakan alat dan media baik berupa benda maupun bukan benda yang membantunya dalam mendidik peserta didik yang pada saat itu adalah umat Islam periode awal yang dalam istilah ilmu Hadis dikenal dengan sebutan Sahabat Nabi. Sebagai generasi emas yang telah di didik langsung oleh Rasulullah Saw., para sahabat menjadi manusia seutuhnya sebagaimana tujuan dari pendidikan Islam.

Berikut adalah hadis-hadis tentang alat dan media yang digunakan oleh Rasulullah Saw. dalam proses pendidikan yang berhasil penulis lacak dari kitab-kitab induk Hadis melalui Software, Kitab 9 Imam Hadis seperti di bawah ini: 


\section{Rasulullah Saw. sebagai media pendidikan}

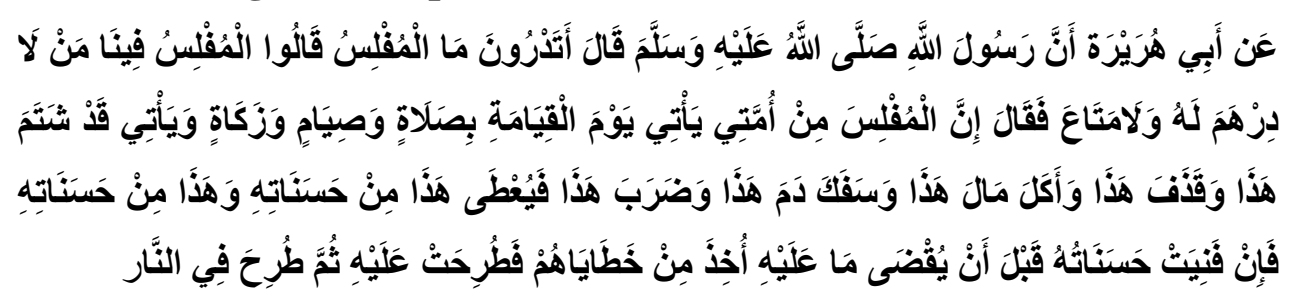

Abu Hurairah meriwayatkan bahwa Rasulullah saw bersabda: "Tahukah kalian apa yang dimaksud dengan al-muflis(bangkrut) ?" Sahabat menjawab, "Al-muflis dikalangan kami orang yang tidak memiliki uang dan harta benda." Rasulullah bersabda: "Sesungguhnya al-muflis dikalangan umatku adalah orang yang datang pada hari qiamat membawa pahala shalat, puasa, dan zakat. Selain itu, ia juga memfitnah, menuduh (berbuat maksiat), memakan harta orang lain (dengan cara tidak halal), menumpahkan darah, dan memukul orang lain. Lalu masing-masing kesalahan itu ditebus dengan kebaikan (pahala)nya. Setelah kebaikan (pahala)nya habis sebelum kesalahannya terselesaikan, maka dosa orang dizaliminya itu dilemparkan kepadanya, kemudian ia dilemparkan kedalam neraka.” (HR. Muslim dan At-Tirmidzi)

Dalam hadis di atas terlihat bahwa Rasulullah Saw. memfungsikan dirinya sebagai mediator, Beliau ajukan pertanyaan kepada para sahabatnya. Beliau dengarkan jawaban mereka, kemudian beliau menjelaskan inti masalah yng sedang dibicarakan sehingga tidak ada lagi tanda tanya dalam pikiran para sahabat, melalui beliau peserta didik mendapat informasi. Dengan demikian beliau adalah media pembelajaran.

Hadis di atas menginformasikan bahwa media yang diterapkan Nabi Muhammad Saw. agar ajaran Agama Islam dapat diterima dengan mudah oleh umatnya, antara lain dapat dilihat dengan melalui media perbuatan Nabi Muhammad Saw. sendiri, di mana beliau memberikan contoh langsung yang dikenal dengan istilah uswah hasanah (contoh teladan yang baik).

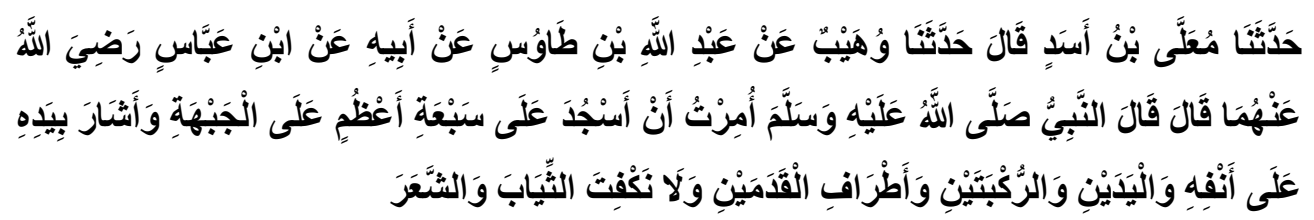

Telah menceritakan kepada kami Mu'alla bin Asad berkata, telah menceritakan kepada kami Wuhaib dari 'Abdullah bin Thawus dari Bapaknya dari Ibnu 'Abbas ra, ia berkata, "Nabi saw bersabda: "Aku diperintahkan untuk melaksanakan sujud dengan 
tujuh tulang (anggota sujud); kening -beliau lantas memberi isyarat dengan tangannya menunjuk hidung- kedua telapak tangan, kedua lutut dan ujung jari dari kedua kaki dan tidak boleh menahan rambut atau pakaian (sehingga menghalangi anggota sujud)." (HR. Bukhari)

Dalam hadis ini, Rasulullah saw menyebutkan anggota-anggota tubuh yang harus menyentuh lantai ketika bersujud dalam shalat. Anggota-anggota tubuh itu adalah kening, kedua telapak tangan, kedua lutut, dan ujung jari kedua kaki. Ketika menyebutkan kening, beliau menunjuk hidung sebagai penekan bahwa hidung itu juga harus menyentuh lantai. Dalam hal ini beliau telah menggunakan media hidung dalam pembelajaran terhadap para sahabatnya.

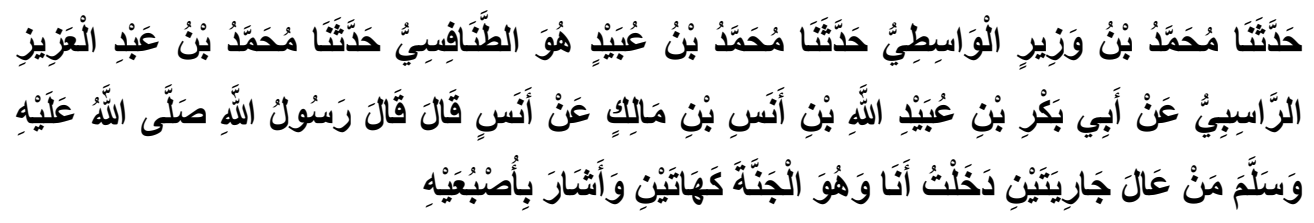

Telah menceritakan kepada kami Muhammad bin Wazir Al Wasithi, telah menceritakan kepada kami Muhammad bin Ubaid Ath Thannafisi, telah menceritakan kepada kami Muhammad bin Abdul Aziz Ar Rasibi dari Abu Bakr bin Ubaidullah bin Anas bin Malik dari Anas ia berkata; Rasulullah saw bersabda: "Barangsiapa yang memelihara dua orang anak wanita, maka aku dan ia akan masuk ke dalam surga seperti kedua (jari) ini." Beliau sambil memberi isyarat dengan kedua jari telunjuknya. (HR. At-Tirmidzi)

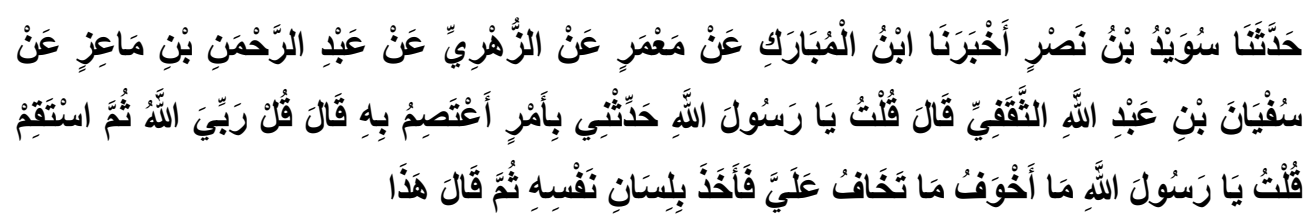

Telah menceritakan kepada kami Suwaid bin Nashr telah mengkhabarkan kepada kami Ibnu Al Mubarak dari Ma'mar dari Az Zuhri dari Abdurrahman bin Ma'iz dari Sufyan bin Abdullah Ats Tsaqafi berkata: Aku berkata: Wahai Rasulullah, ceritakan padaku suatu hal yang aku jadikan pedoman. Rasulullah Shallallahu 'alaihi wa salam bersabda: "Katakan: Rabbku Allah kemudian beristiqamahlah." Aku bertanya: Wahai Rasulullah, apa yang paling anda takutkan padaku? Beliau memegang lidah beliau lalu menjawab: "Ini." (HR. At-tirmidzi) 
Ketika menjelaskan yang salah, Rasulullah Saw. menggunakan media jari dan lidahnya "dengan sebab ini" sambil menunjuk lidahnya. Dengan demikian, beliau telah menggunakan media jari dan lidah untuk menyampaikan pesan. Penggunaan media ini tentu sangat efektif untuk menjelaskan maksud pelajaran yang diberikan oleh beliau.

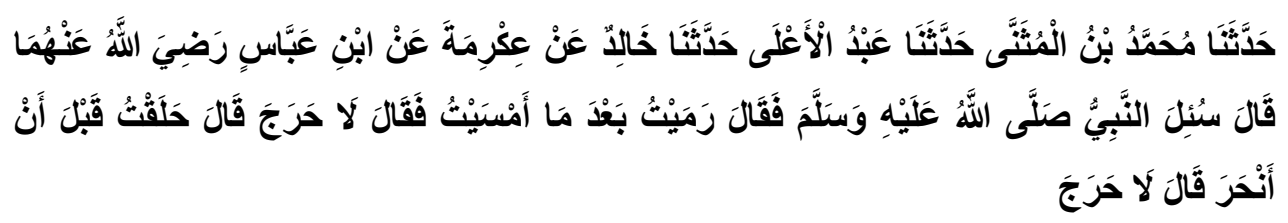

Telah menceritakan kepada kami Muhammad bin Al Mutsanna telah menceritakan kepada kami 'Abdul A'laa telah menceritakan kepada kami Khalid dari 'Ikrimah dari Ibnu 'Abbas ra berkata: "Nabi saw ditanya, kata orang itu: "Aku melempar jumrah setelah sore". Beliau bersabda: "Tidak dosa". Orang itu berkata, lagi: "Aku mencukur rambut sebelum menyembelih hewan qurban". Beliau bersabda: "Tidak dosa". (HR. Bukhari )

Hadis ini menginformasikan bahwa Nabi saw ditanya tentang dua hal sehubungan dengan pelaksanaan ibadah haji, yaitu tentang menyembelih hewan sebelum melontar jumrah dan mencukur rambut sebelum menyembelih, kedua pertanyaan itu secara berurutan dijawab oleh Rasulullah saw dengan menggunakan isyarat tangan yang berarti "tidak apa-apa atau tidak salah". Di sini beliau menggunakan tangan sebagai media pembelajaran.

\section{Media pendidikan bukan manusia}

1. Matahari dan Bulan

Matahari dan bulan adalah benda langit yang dapat disaksikan oleh manusia dengan jelas karena keduanya memiliki cahaya yang terang. Rasulullah saw menggunakan keduanya sebagai media pembelajaran.

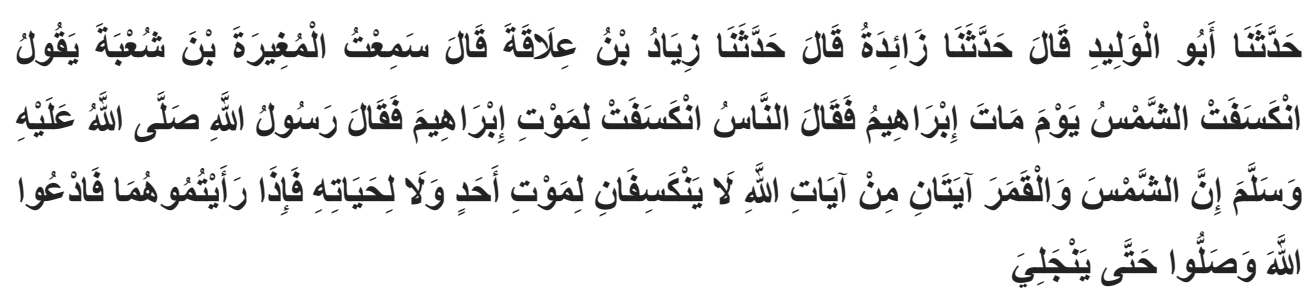


Telah menceritakan kepada kami Abu al-Walid berkata, telah menceritakan kepada kami Zaidah berkata, telah menceritakan kepada kami Ziyad bin 'Alaqah berkata, "Aku mendengar al-Mughirah bin Syu'bah berkata, "Telah terjadi gerhana matahari ketika wafatnya Ibrahim. Kemudian Rasulullah saw bersabda: "Sesungguhnya matahari dan bulan adalah dua tanda dari tanda-tanda kebesaran Allah, dan ia tidak akan mengalami gerhana disebabkan karena mati atau hidupnya seseorang. Jika kalian melihat gerhana keduanya, maka berdo'alah kepada Allah dan dirikan shalat hingga (matahari) kembali nampak.” (HR. Bukhari)

Informasi yang terkandung dalam hadis di atas adalah:

a. Telah terjadi gerhana matahari pada saat kematian Ibrahim, putra Rasulullah saw.

b. Sahabat menduga bahwa gerhana itu terjadi karena kematian Ibrahim.

c. Rasulullah saw menegaskan bahwa gerhana matahari dan bulan merupakan tanda-tanda kebesaran Allah.

d. Peristiwa gerhana itu tidak ada hubungannya dengan kematian atau kelahiran seseorang.

Ibnu Hajar menjelaskan bahwa Rasulullah Saw. menegaskan bahwa peristiwa gerhana matahari dan bulan itu merupakan tanda-tanda kebesaran Allah, yang dikirimkannya untuk menakut-nakuti manusia. Tepat pada waktu terjadinya peristiwa gerhana matahari, beliau menjadikannya sebagai media untuk menanamkan keimanan kepada para sahabat sekaligus membersihkan akidah mereka dari unsur-unsur khurafat.

2. Mimbar

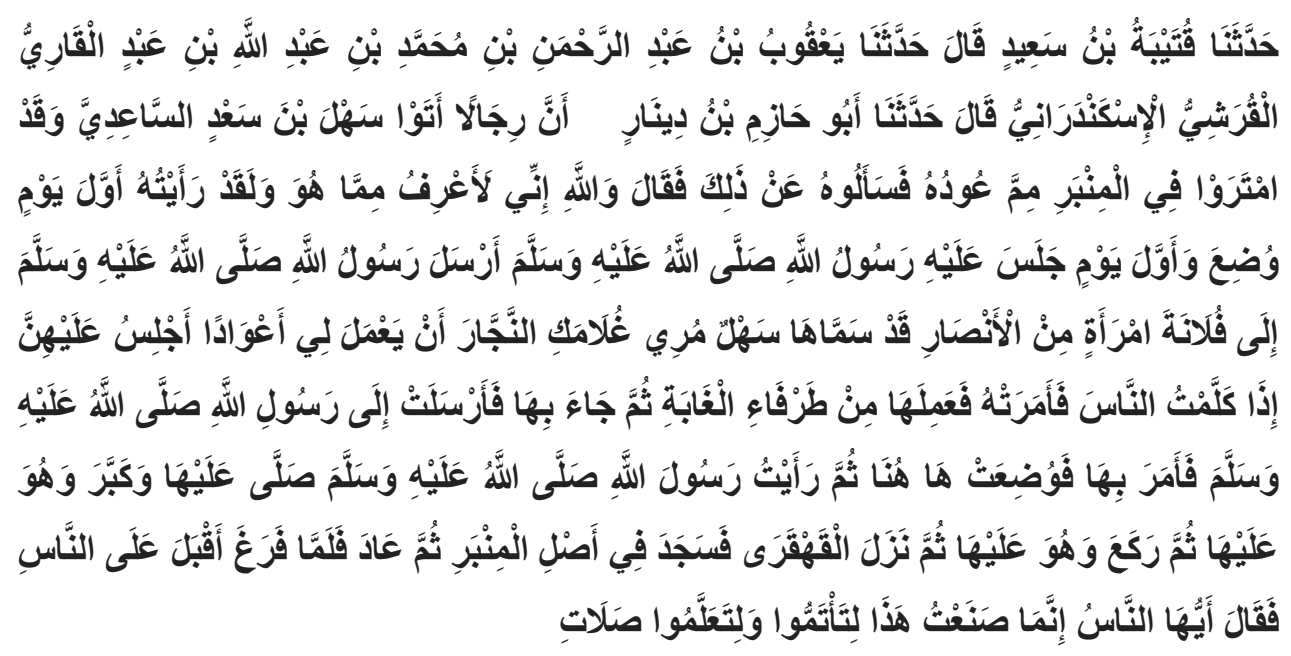


Telah menceritakan kepada kami Qutaibah bin Sa'id berkata, telah menceritakan kepada kami Ya'qub bin 'Abdurrahman bin Muhammad bin 'Abdullah bin 'Abdul Qari al-Qurasyi al-Iskandarani berkata, telah menceritakan kepada kami Abu Hazim bin Dinar bahwa ada orang-orang mendatangi Sahl bin Sa'd As Sa'idi yang berdebat tentang mimbar dan bahan membuatnya? Mereka menanyakan hal itu kepadanya. Sahl lalu berkata, "Demi Allah, akulah orang yang paling mengerti tentang masalah ini. Sungguh aku telah melihat hari pertama mimbar tersebut dipasang dan hari saat Rasulullah saw duduk di atasnya. Rasulullah saw mengutus orang untuk menemui seorang wanita Anshar, yang namanya sudah disebutkan oleh Sahl, Sahl lalu berkata, "Perintahkanlah budak lelakimu yang tukang kayu itu untuk membuat mimbar bertangga, sehingga saat berbicara dengan orang banyak aku bisa duduk di atasnya." Maka kemudian wanita itu memerintahkan budak lelakinya membuat mimbar yang terbuat dari batang kayu hutan. Setelah diberikan kepada wanita itu, lalu itu mengirimnya untuk Rasulullah saw. Maka Beliau memerintahkan orang untuk meletakkan mimbar tersebut di sini. Lalu aku melihat Rasulullah saw shalat diatasnya. Beliau bertakbir dalam posisi di atas mimbar lalu rukuk dalam posisi masih di atas mimbar. Kemudian Beliau turun dengan mundur ke belakang, lalu sujud di dasar mimbar, kemudian Beliau mengulangi lagi (hingga shalat selesai). Setelah selesai, beliau menghadap kepada orang banyak lalu bersabda: "Wahai sekalian manusia, sesungguhnya aku berbuat seperti tadi agar kalian mengikuti dan agar kalian dapat mengambil pelajaran tentang tata cara shalatku." (HR. Bukhari)

Hadis di atas menginformasikan bahwa Rasulullah saw mendidik para sahabat agar menjadi orang yang pemurah. Beliau memotivasi mereka untuk bersedekah. Dalam menyampaikan materi tersebut, beliau menggunakan mimbar sebagai media. Hal ini dilakukan agar sahabat dapat melihat beliau dengan jelas, sehingga informasi yang disampaikan dapat diterima secara baik.
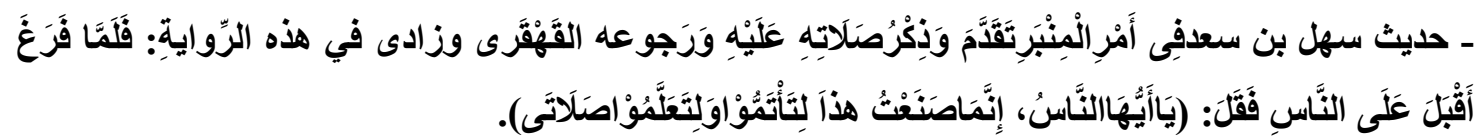

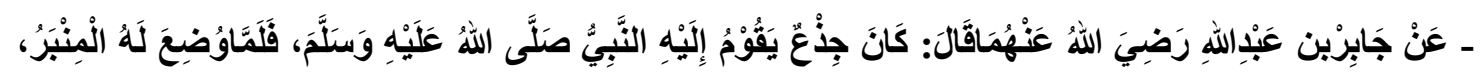

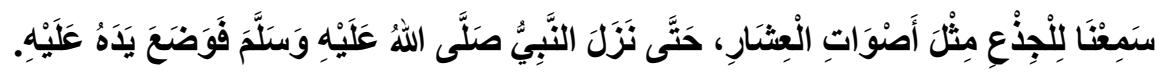

- Hadits Sahl bin Sa'd yang berkaitan dengan mimbar. Sahl menyebutkan bahwa Nabi Muhammad Saw. mengerjakan sholat diatas mimbar kemudian mundur ke belakang 
dan pada hadits ini ditambahkan, "setelah menyelesaikan sholat, Nabi Muhammad Saw. menghadapkan wajahnya kepada orang-orang (yang bermakmum) dan berkata, aku melakukan hal ini agar kalian mengikutiku dan mempelajari bagaimana aku mengerjakan sholat”.

- Diriwayatkan dari Jabir bin 'Abdullah r.a.: Nabi Muhammad Saw. biasa berdiri diatas sebuah pohon pohon kurma (ketika menyampaikan khutbah). Ketika sebuah mimbar disediakan untuk Nabi saw. kami mendengar pohon kurma itu menangis seperti unta betina yang bunting hingga Nabi saw. turun dari mimbarnya dan mengelus pohon itu.

\section{Sutra dan Emas}

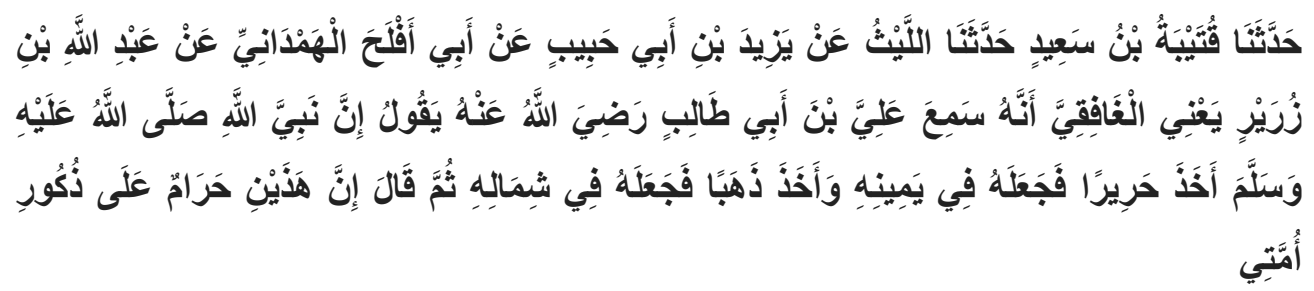

Telah menceritakan kepada kami Qutaibah bin Sa'id berkata, telah menceritakan kepada kami al-Laits dari Yazid bin Abu Habib dari Abu Aflah Al Hamdani dari Abdullah bin Zurair -yaitu al-Aghafiqi-Bahwasanya ia mendengar Ali bin Abu Thalib ra, "Rasulullah pernah mangambil sutera lalu meletakkannya pada sisi kanannya, dan mengambil emas lalu meletakkannya pada sisi kirinya. Kemudian beliau bersabda: "Sesugguhnya dua barang ini haram bagi umatku yang laki-laki." (HR. Abu Dawud)

Dalam hadis ini Rasulullah saw menyebutkan dengan tegas bahwa sutra dan emas itu bukan pakaian kaum laki-laki, beliau memegang kedua benda itu, masingmasing benda di tangan kiri dan kanan, lalu menegaskan kedua barang ini diharamkan bagi umatnya yang laki-laki. Itu berarti bahwa Rasulullah saw telah menggunakan media barang sebenarnya untuk mempermudah para sahabat memahaminya.

\section{Perumpamaan}

Biasanya, perumpamaan dapat dipahami oleh orang-orang yang cerdas, ahli pikir, atau pemuka masyarakat. Perumpamaan merupakan sarana pendidikan yang efektif dalam melanggengkan suatu informasi. Dalam sabdanya, Rasulullah saw. banyak sekali memanfaatkan perumpamaan. 


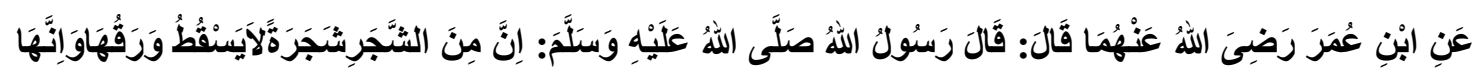

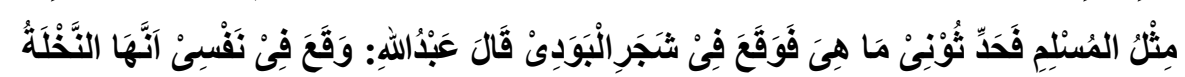

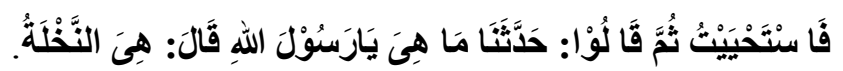

Dari Ibnu Umar ra. berkata: "Rasulullah saw. bersabda: "sesungguhnya diantara pohon-pohon itu ada pohon yang daunnya tidak gugur, sesungguhnya itulah perumpamaan orang muslim, maka ceritakanlah kepada kami pohon apakah itu?”. Orang-orang menduga pohon di padang pasir. Abdullah berkata: "Tergores dalam hatiku bahwa pohon itu adalah pohon kurma, namun saya malu”. Kemudian mereka berkata: "Ceritakan kepada kami pohon apakah itu wahai Rasulullah?" Beliau bersabda: "Dia itu pohon kurma".

\section{Jari}

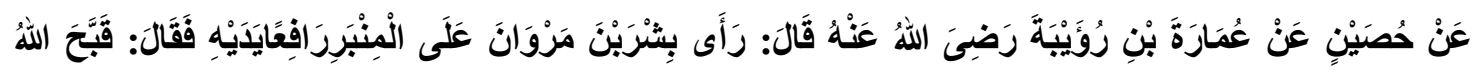

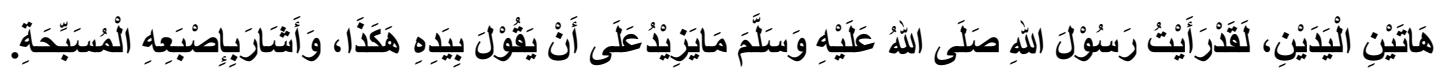
Diriwayatkan dari Hushain, dari Umarah bin Ruaibah r.a., ia berkata bahwa dia melihat Bisyr bin Marwan berkhotbah diatas mimbar sambil mengangkat kedua tangannya lalu Umarah mengatakan "Semoga Allah mencelakakan kedua tangan ini. Sungguh aku pernah melihat Rasulullah berkhotbah hanya berisyarat dengan tangannya sebagai berikut”. Umarah berisyarat dengan menggunakan jari telunjuknya. (H.R. Muslim)

\section{Gambar/Foto}

Di antara media pendidikan, gambar/foto adalah media yang paling umum dipakai. Dia merupakan bahasa yang umum, yang dapat dimengerti dan dinikmati di mana-mana. Oleh karena itu, pepatah Cina yang mengatakan bahwa sebuah gambar berbicara lebih banyak dari pada seribu kata.

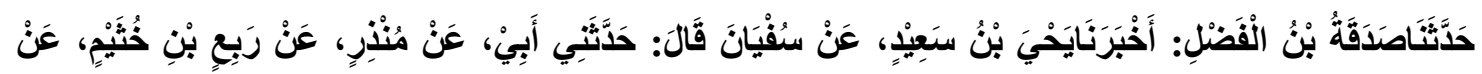

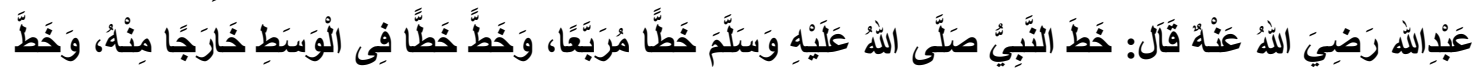

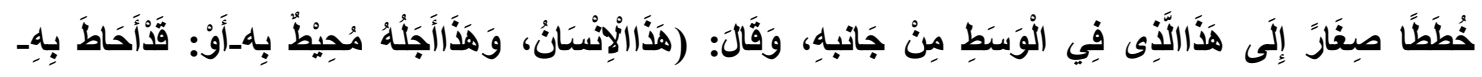

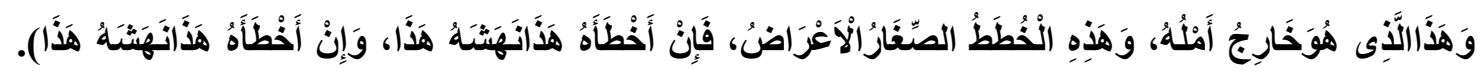


"Telah menceritakan pada kami Sodaqoh bin Fadhil, telah memberikan kabar kepadaku Yahya bin Sa'id dari Sofyan, beliau bersabda: Telah menceritakan kepadaku bapak ku dari Mundzir dari Robi' bin Khusein dan Abdullah R.A, Beliau bersabda: Nabi SAW pernah membuat garis (gambar) persegi empat dan membuat suatu garis lagi di tengah-tengah sampai keluar dari batas(persegi empat), kemudian beliau membuat banyak garis kecil yang mengarah ke garis tengah dari sisi-sisi garis tepi, lalu beliau bersabda: Beginilah gambaran manusia. Garis persegi empat ini adalah ajal yang pasti bakal menimpanya, sedang garis yang keluar ini adalah anganangannya, dan garis-garis kecil ini adalah berbagai cobaan dan musibah yang siap menghadangnya. Jika ia terbebas dari cobaan yang satu, pasti akan tertimpa cobaan lainnya,jika ia terbebas dari cobaan yang satunya lagi, pasti akan tertimpa cobaan lainnya lagi”. (HR. Bukhori)

Nabi Muhammad Saw. menjelaskan garis lurus yang terdapat di dalam gambar adalah manusia, gambar empat persegi yang melingkarinya adalah ajalnya, satu garis lurus yang keluar melewati gambar merupakan harapan dan anganangannya sementara garis-garis kecil yang ada disekitar garis lurus dalam gambar adalah musibah yang selalu menghadang manusia dalam kehidupannya di dunia.

Dalam gambar ini Nabi Muhammad Saw. menjelaskan tentang hakikat kehidupan manusia yang memiliki harapan, angan-angan dan cita-cita yang jauh ke depan untuk menggapai segala yang ia inginkan di dalam kehidupan yang fana ini, dan ajal yang mengelilinginya yang selalu mengintainya setiap saat sehingga membuat manusia tidak mampu menghindar dari lingkaran ajalnya, sementara itu dalam kehidupannya, manusia selalu menghadapi berbagai musibah yang mengancam eksistensinya, jika ia dapat terhindar dari satu musibah, musibah lainnya siap menghadang dan membinasakannya, artinya setiap manusia tidak mampu menduga atau menebak kapan ajal akan menjemputnya.

Secara tidak langsung Nabi Muhammad Saw.memberikan nasehat pada mereka untuk tidak (sekedar melamun) berangan-angan panjang saja (tanpa realisasi), dan mengajarkan pada mereka untuk mempersiapkan diri menghadapi kematian.

Hadis ini menunjukan kepada kita betapa Rasulullah Saw. seorang pendidik yang sangat memahami metode yang baik dalam menyampaikan pengetahuan kepada manusia, beliau menjelaskan suatu informasi melalui gambar agar lebih mudah dipahami dan diserap oleh akal dan jiwa. 


\section{KESIMPULAN}

Hadis-hadis Rasulullah Saw. di atas adalah sumber inspirasi dan akar keteladanan bagi pelaksanaan pendidikan Islam zaman sekarang. Dari hadis-hadis di atas kita dapat membaca bagaimana praktik pendidikan Islam yang telah dilaksanakan oleh Rasulullah Saw. 14 abad yang silam dan ternyata dalam praktik pendidikannya Rasulullah Saw. juga menggunakan alat dan media untuk memudahkan terserapnya materi dan tercapainya tujuan pendidikan.

Dalam praktiknya, Rasulullah Saw. menggunakan beberapa media dan alat ketika mendidik para sahabatnya seperti benda-benda yang ada disekitarnya atau menjadikan dirinya sendiri menjadi mediator untuk mendekatkan pemahaman tentang materi yang di ajarkan kepada para sahabat yang menjadi peserta didik pada saat itu. Walaupun sebagian media dan alat yang digunakan oleh Rasulullah Saw. tidak bisa digunakan lagi untuk zaman ini karena tidak sesuai lagi tapi spirit untuk mencapai tujuan pendidikan dengan menggunakan media dan alat pendidikan wajib kita jadikan inspirasi dan motivasi bagi kita dalam menjalankan pendidikan baik di lingkungan keluarga maupun di lingkungan sekolah, perkuliahan dan lain-lain.

Sehingga dengan membaca dan menjadikan Hadis-hadis Rasulullah Saw. di atas sebagai inspirasi dan motivasi dalam pendidikan zaman sekarang ini membuat suasana pendidikan yang kita jalankan saat ini terasa seperti tarbiyah nabawi yang di praktikkan oleh Nabi Muhammad Saw. dan akan berhasil mencapai tujuan seperti berhasilnya Nabi Muhammad Saw. mendidik para sahabatnya yang kelak di kemudian hari setelah wafatnya Nabi Muhammad Saw. juga berhasil mengajar dan mendidik para tabiin.

\section{DAFTAR PUSTAKA}

Asnawir dan Basyiruddin Usman, Media Pembelajaran, Ciputat Press, Jakarta Selatan, 2002.

Al-Bukhari, Sahih al-Bukhari, Juz I, Beirut : Dar al-Fikr, 1981.

At-Tirmizi, Sunan at-Tirmizi, Juz I, Beirut : Dar al-Fikr, t.t.

Daradjat, Zakiah, Metode Khusus Pengajaran Agama Islam, Jakarta: Bumi Aksara, 1995

Husaini Usman, Manajemen: Teori, Praktik, dan Riset Pendidikan Jakarta: Bumi Aksara, 2011 
Jalaluddin As-Suyuti, Tadrib Ar-Rawi,Beirut:Dar Al-Fikr, 1995

Mahmud at-Tahhan, Taisir Mustalah al-Hadis. Beirut : Dar al-Kutub, 2000.

Muhammad 'Ajjaj al-Khatib, Usul al-Hadis. Beirut : Dar al-Fikr, 1989.

Muhammad Fu'ad Abd al-Baqi, al-Mu'jam al-Mufahras li Alfaz al-Qur'an al-Karim. Beirut : Dar al-Ma'arif,

Muhammad Ibn Mukaram Ibn Manzhur. Lisan al-Arab. Juz II. Beirut : Dar al-Ma'arif, 1992.

Muhammad Mustafa Azami, Studies in Hadith Methodology and Literature. Kuala Lumpur : Islamic Book Trust, 1977.

Muhammad Jamal ad-Din al-Qasimi, Qawa'id at-Tahdis. Beirut : Dar al-Kutub alIlmiah, 1980

Syafaruddin, dkk. Ilmu Pendidikan Islam. Jakarta : Hijri, 2008.

Umar, Bukhari. 2012. Hadits Tarbawi. Jakarta : Amzah 